\title{
Development of spatial scaling technique of forest health sample point information
}

\author{
Jun Hee Lee ${ }^{1}$, Ji Eun Ryu ${ }^{1}$, Hye In Chung ${ }^{1}$, YuYoung Choi ${ }^{1}$, Seong Woo Jeon ${ }^{1 *}$, Sun Hee Kim²
}

Organization : ${ }^{1}$ Department of Environmental Science and Ecological Engineering,

Graduate School, Korea University 145 Anam-ro, Seongbuk-gu, Seoul, 02841, Korea

(leejh9, eepps_korea)@korea.ac.kr

${ }^{2}$ National Institute of Forest Science, Korea

Commission III, WG III/1

KEY WORDS: Forest, Forest management, Forest Health, Species diversity, Shannon’s index, Spatial interpolation, Kriging, IDW

\begin{abstract}
:
Forests provide many goods, Ecosystem services, and resources to humans such as recreation air purification and water protection functions. In rececnt years, there has been an increase in the factors that threaten the health of forests such as global warming due to climate change, environmental pollution, and the increase in interest in forests, and efforts are being made in various countries for forest management. Thus, existing forest ecosystem survey method is a monitoring method of sampling points, and it is difficult to utilize forests for forest management because Korea is surveying only a small part of the forest area occupying 63.7\% of the country (Ministry of Land Infrastructure and Transport Korea, 2016). Therefore, in order to manage large forests, a method of interpolating and spatializing data is needed. In this study, The $1^{\text {st }}$ Korea Forest Health Management biodiversity Shannon;s index data (National Institute of Forests Science, 2015) were used for spatial interpolation. Two widely used methods of interpolation, Kriging method and IDW(Inverse Distance Weighted) method were used to interpolate the biodiversity index. Vegetation indices SAVI, NDVI, LAI and SR were used. As a result, Kriging method was the most accurate method.
\end{abstract}

\section{INTRODUCTION}

Forests provide human beings with many goods, services, and resources, such as recreation, atmospheric purification, and water conservation. In recent years, there have been increasing threats to the health of forests such as global warming due to climate change, environmental pollution, and the growing interest in forests, and thus efforts are being made in various countries for forest management. The sustainable forest management proposed in the Montreal process, which is an international forest treaty, means sustainable management of the forests in terms of ecological, economic, social and cultural functions in consideration of intergenerational equity. Seven criteria for evaluating the performance of management were presented. In this reason, countries around the world are actively working on the establishment of a forest health survey index using the criteria for conservation of biodiversity and the third standard for maintaining health and vitality of forest ecosystems(2015, National Institute of Forest Science, 2015).

In Korea, Forest service, conducted the 5th National Forest Investment (2006 2010) with 4,000 plots based on the "Fifth Forest Basic Plan (2008 2017)" as headquarters and 967 specimens examined the health and vitality of forest in korea. The survey consist of 28 indexes in 4 major categories (tree, vegetation, soil, atmosphere) and 12 survey part.
In United Kingdom, the Forest Health Assessment was conducted to prevent damage to the population and surrounding ecosystems of the UK spruce, which has been declining since the early 1980s. Every year, between June and September, we surveyed about 8400 trees across 350 monitoring plots throughout the UK. Among them, the crown density is the most important factor, and the crown density is evaluated according to the transparency observed especially at the bottom of the tree crown.

In case of United states, The area of Great Bay forest in summer and fall of 2006 was divided into several sections, and the forests of each section were measured to evaluate the health of trees and the characteristics of ecosystem populations by each area were identified. The New Hampshire Natural Resources Association assessed health by dividing 763 acres into ten natural populations.

In this way, existing forest ecosystem survey methods are sampling points of sampling points, and they are surveying a very small part of the forest area occupying $63.7 \%$ of Korea's national territory (as of 2016). It is difficult to manage forest. Therefore, in order to grasp and manage the status of forests nationwide, it is necessary to generate data for the whole country using The 1st Korea Forest Health Management data. In order to generate spatial data, spatial interpolation method

\footnotetext{
* Corresponding author
} 
should be used. Prior to this, appropriate indices were selected from among the first forest health and vitality survey data. In the case of nominal data among The 1st Korea Forest Health Management, it was judged that it was difficult to spatialize, and the biodiversity index determined to be most suitable for spatialization among continuous data was selected.

The biodiversity index is used as a measure of how diverse the composition of vegetation is, and thus is being used as an effective method for determining the stability and health status of forests(Yang et al. 2001). The biodiversity indices are Simpson's index and Shannon's index (Gorelick, 2018). These two biodiversity indices are used to study species diversity in forest communities.

In this study, we used Shannon's index (Ludwig et al, 1988), which is considered to be a suitable method for calculating the vegetation data of random sampling points that are related to the uncertainty theory, It was judged to be a region with high forest health.

The spatialization method used in this study uses IDW and kriging methods, which are typical spatialization methods using GIS (Geographic Information System), and Cokriging method using various vegetation indices extracted using Landsat8 image with relatively high resolution and DEM(Digital Elevation Model) were used to evaluate the accuracy.

\section{METHOD}

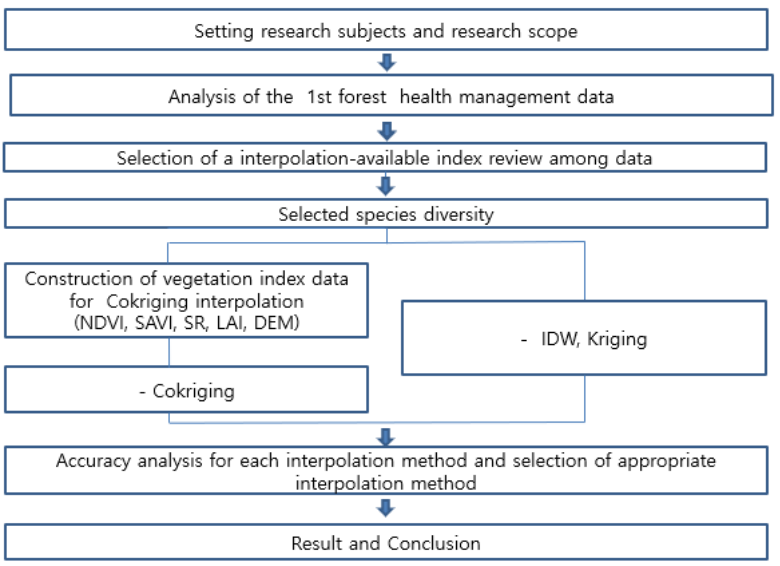

Figure 1. Flow chart

\subsection{Study Area}

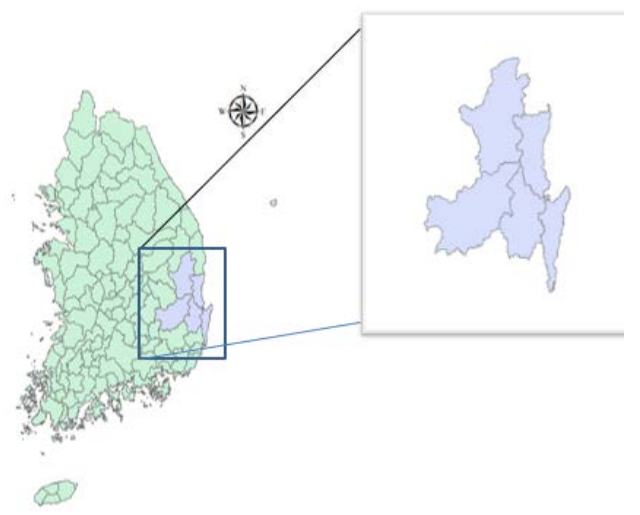

Figure 2. study area
In this study, study area is Gyeongbuk area, which has the largest number of sampling points. Among them, in order to see the health of Pohang Forest, where the industrial structure is composed mainly of heavy and chemical industries, many environmental pollutants are emitted. Forest sampling points of five watershed including Pohang.

\subsection{Landsat Satellite image}

In this study, images of Landsat OLI / TIRS are used. In the case of the Landsat image, it is a medium resolution image with a resolution of $30 \mathrm{~m}$. It is able to explore a relatively wide area, utilize various band regions, extract vegetation index and poetic index, and analyze various features such as urban spatial behavior, vegetation analysis, It is also used in the field.

Kim (2015) conducted a study to analyze spatiality after obtaining NDVI (Normalized Difference Vegetation Index) and NDBI (Normalized Difference Built-up Index) 2011) extracted NDVI using Landsat satellite image and analyzed the temperature change according to the usage area in urban area. Choi et al. (2014) studied the method of estimating vegetation cover index using NDVI of Landsat 8 OLI image and Yoon et al. (2017) extracted NDVI using Landsat 8 OLI image, And the proposed regression equation was used to analyze the relationship, and proposed a conversion equation useful for soil erosion modeling. In addition, Kwon et al. (2009) analyzed the correlation between surface temperature and vegetation index in urban areas using Landsat TM images.

news and results of the paper in words understandable also to non-specialists.

\begin{tabular}{|c|c|c|c|}
\hline Landsat 8 & Bands & $\begin{array}{c}\text { Wavelength } \\
\text { (micrometers) }\end{array}$ & $\begin{array}{l}\text { Resolution } \\
\text { (meters) }\end{array}$ \\
\hline \multirow{11}{*}{$\begin{array}{c}\text { Operational } \\
\text { Land Imager } \\
\text { (OLI) } \\
\text { and } \\
\text { Thermal } \\
\text { Infrared } \\
\text { Sensor } \\
\text { (TIRS) }\end{array}$} & $\begin{array}{c}\text { Band1 } \\
\text { (Ultra Blue) }\end{array}$ & $0.43-0.45$ & 30 \\
\hline & $\begin{array}{l}\text { Band2 } \\
\text { (Blue) }\end{array}$ & $0.45-0.51$ & 30 \\
\hline & $\begin{array}{c}\text { Band3 } \\
\text { (Green) }\end{array}$ & $0.53-0.59$ & 30 \\
\hline & $\begin{array}{l}\text { Band4 } \\
\text { (Red) }\end{array}$ & $0.64-0.67$ & 30 \\
\hline & $\begin{array}{l}\text { Band5 } \\
\text { (NIR) }\end{array}$ & $0.85-0.88$ & 30 \\
\hline & $\begin{array}{c}\text { Band6 } \\
\text { (SWIR 1) }\end{array}$ & $1.57-1.65$ & 30 \\
\hline & $\begin{array}{c}\text { Band7 } \\
\text { (SWIR 2) }\end{array}$ & $2.11-2.29$ & 30 \\
\hline & $\begin{array}{c}\text { Band8 } \\
\text { (Panchromatic) }\end{array}$ & $0.50-0.68$ & 15 \\
\hline & $\begin{array}{c}\text { Band9 } \\
\text { (Cirrus) }\end{array}$ & $1.36-1.38$ & 30 \\
\hline & $\begin{array}{c}\text { Band10 } \\
\text { (Thermal } \\
\text { Infrared1) }\end{array}$ & $10.60-11.19$ & $100 *(30)$ \\
\hline & $\begin{array}{l}\text { Band11 } \\
\text { (Thermal } \\
\text { Infrared2) }\end{array}$ & $11.50-12.51$ & $100 *(30)$ \\
\hline
\end{tabular}

\subsection{The $1^{\text {st }}$ Forest Health management}

National Institute of Forest Science of Korea will provide 1000 national fixed-point nationwide, which is $25 \%$ of the 5th National Forest Resources Survey (2006 2010, Korea Forest 
Service) sampling points, conducted in the past four years (2011 2014) Five-year periodic monitoring survey system "(200 items in total for 5 years, totaling about 1,000 studies), and 5 years later, the same sample points are researched again. ). As a result of evaluating the forest health of this sampling point, $86.6 \%$ of Korean forests were evaluated as healthy forests and $8.1 \%$ of them were 'very healthy'. $13.2 \%$ of the forests with slightly poorer health and $0.2 \%$ of the very weak forests.

\subsection{Vegetation index}

In this study, using 4 vegetation index NDVI(Normalized Differenced Vegetation Index, NDVI), SAVI(Soil Adjusted Vegetation Index, SAVI), SR(Simple Ratio, SR), LAI(Leaf Area Index, LAI).

The NDVI is a normal vegetation index that values the difference between visible light and near infrared light and emphasizes the reflection characteristics of vegetation so that the area with less vegetation is -1 and the area with the most active vegetation is 1 (Rouse et al. 1974).

The SAVI is a soil adjusted vegetation index. SAVI is a soil correction factor to prevent the reduction of difference in red visible and near infrared reflectance of the canopy by background soil. When $\mathrm{L}$ is 0.5 , the change in soil brightness is minimal and no additional correction is needed for other soil(Huete, 1988).

The SR index is an exponential index that utilizes the red and near infrared regions and is widely used in multispectral data with wide spacing between the bands. In addition, the SR index is a ratio between the red region and the near infrared region and is widely used with NDVI. Lee et al(2013), In order to compare the spectroscopic characteristics of the infected trees of the pine tree showed that the characteristics of the infection progress stage were changed through the SR and NDVI images from the early stage of infection to the pine tree Respectively.

This LAI index not only directly reflects the seasonal changes of vegetation but also includes radiation, temperature, soil moisture, soil, species differences, stand density, vegetation distribution, and terrain factors.

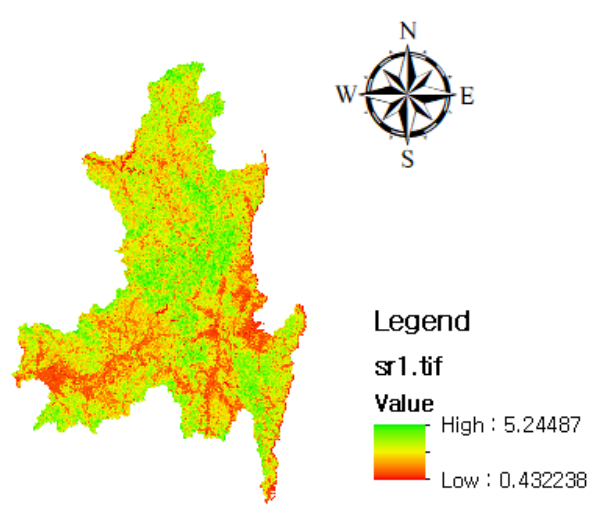

Figure 3. SR

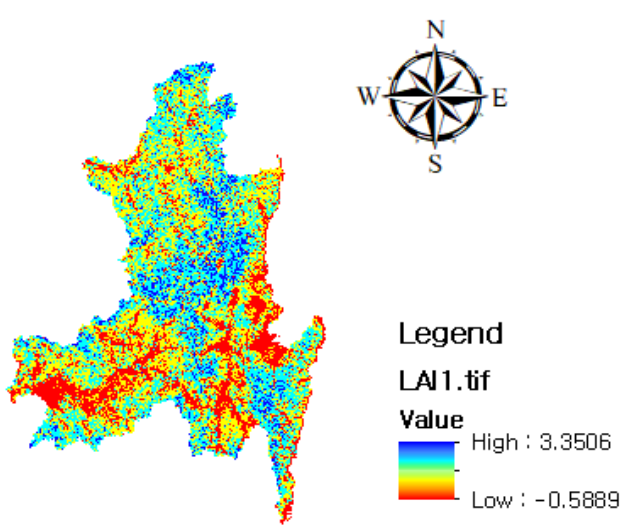

Figure 4. LAI

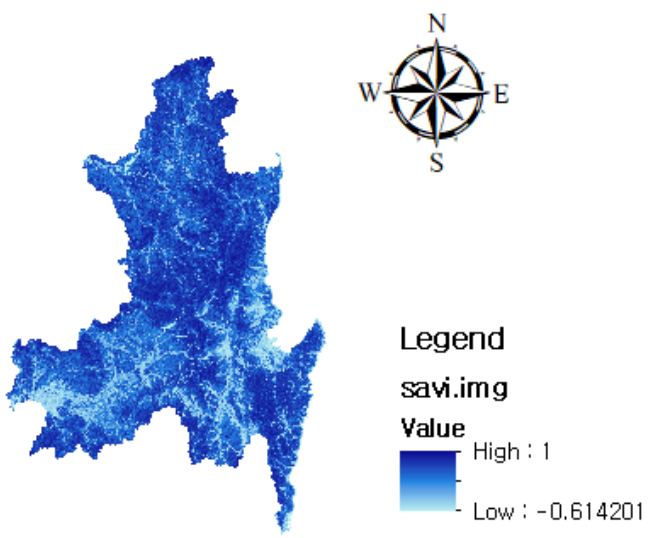

Figure 4. SAVI

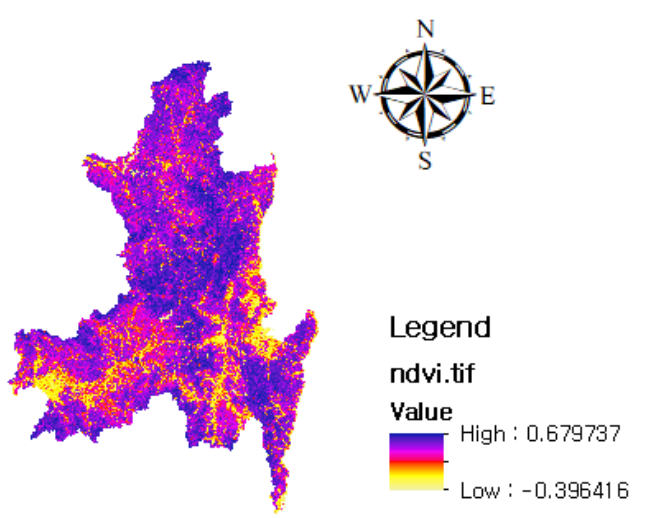

Figure 5. NDVI

\begin{tabular}{|l|l|}
\hline Equation & \\
\hline NDVI & Band5-Band4/Band5+Band4 \\
\hline SR & Band5/Band4 \\
\hline SAVI & $(1+\mathrm{L})($ Band5-Band4)/(Band5+Band4+L) \\
\hline LAI & LAI= 0.7879*SR-0.5889 \\
\hline
\end{tabular}

Table 2. Vegetation Index(Rouse et al. 1974, Huete. 1988) 


\subsection{Spatial Interpolation Method}

Interpolation is a method of estimating extrapolation to the outside of a sampling point, and estimating the temperature, precipitation, and altitude outside the meteorological observation point. It is widely used for spatial expansion of environmental data such as prediction of pollution distribution. Spatial interpolation is largely divided into deterministic and geostatistical methods(Lee et al, 2010)

Deterministic interpolation techniques are classified into global interpolation and local interpolation. The global interpolation method has a global polynomial interpolation that calculates the predicted value using the entire data set. The local interpolation method calculates the predicted value from the measured value within the specific neighborhood value, which is a small spatial area within the experimental area. Inverse Distance Weighted (IDW), local trend surface model, and radial basis function.

Geographical statistical interpolation is used for predictive surface modeling including error of estimation value or uncertainty based on statistical methods. Kriging is a typical technique. Unlike the deterministic interpolation method, a regression equation is generated based on measured values to derive statistical numerical results such as prediction error and standard error.

It is important to use different interpolation methods depending on the properties of each data and to find a method that matches the data attributes. When spatial interpolation is performed based on the same data, the results are different depending on the spatial interpolation method. In this study, we used Kriging and IDW interpolation methods which are consistent with the biodiversity index.

\subsubsection{IDW (Inverse Distance Weighted, IDW)}

It is a technique to generate predictions on the assumption that the values between spatially adjacent points have similarity, while the similarity decreases as the distance between two points increases. It is a technique that sets a weight so that the nearest point from the predicted point has a greater influence than the farther point, and does not generate the prediction error.
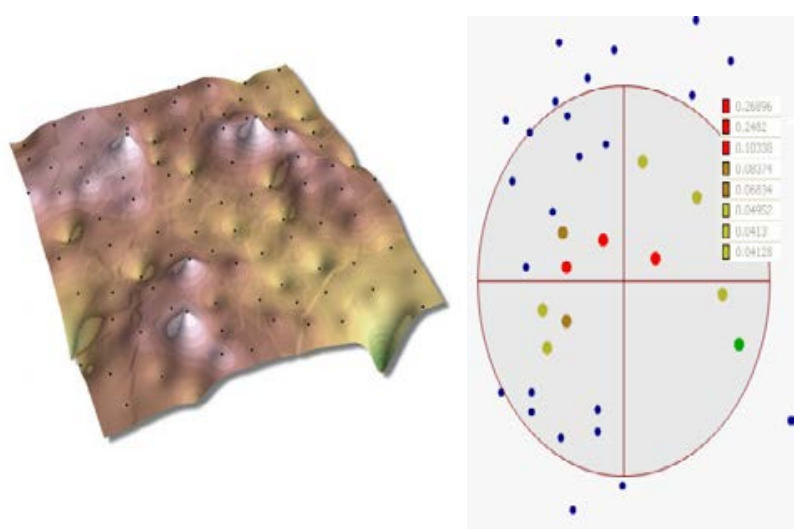

\subsubsection{Kriging.}

2.5.3 One of the geostatistical methods is a spatial interpolation method that includes autocorrelation, which is a statistical relationship between measurements taking into account the trend of the data. Weights are calculated by semivariogram to determine the spatial structure of the data. The weighted linear combination of the observed points is used to estimate the value of the unobserved point. The variogram shows the expected value of squaring the data difference between two points according to the distance between two data, showing the statistical correlation of the data points. Since the empirical variogram is calculated from the observed data, and the theoretical variogram is then used to estimate the variogram of the unobserved point, finding the theoretical variogram is very important in the kriging method. Cokriging is a kriging method that uses two or more variables. When kriging is insufficient, it can be used when there is a quadratic variable that has more data than the variable and has a linear relationship with the variable to be interpolated. In this study, Cokriging was carried out using vegetation index and DEM(Digital Elevation Model) .

Cho et al.(2007) compare spatial accuracies of spatial distribution of PM10 in Seoul using spatial trend model, IDW, BRF, and kriging. Park et al. (2009) analyzed the accuracy of seasonal precipitation distribution by creating a precipitation map using Cokriging using geomorphological parameters for Jeju Island.

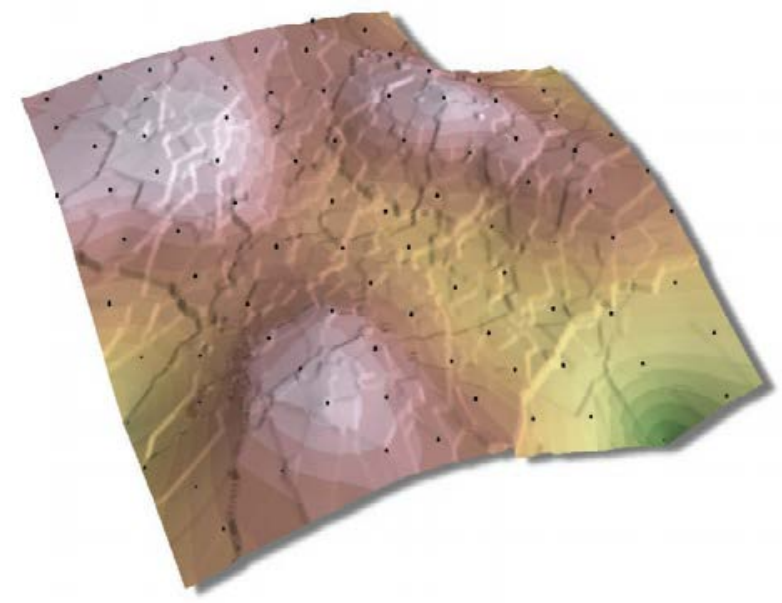

Figure 6. Example of Kriging( ArcUser, 2004)

Figure 6. Example of IDW( ArcUser, 2004) 


\section{RESULT \& CONCLUSION}
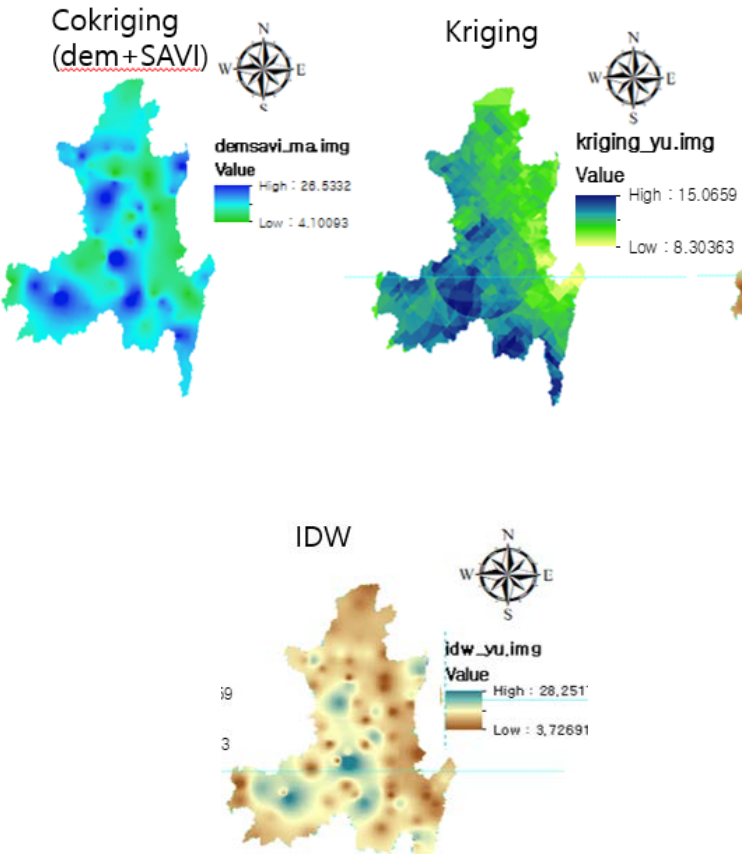

Figure7. Cokriging(DEM+SAVI), Kriging, IDW Result

\begin{tabular}{|c|c|c|c|}
\hline & cokriging(DEM+SAVI) & Kriging & idw \\
\hline $\begin{array}{c}\text { Mean } \\
\text { error }\end{array}$ & 0.13821 & 0.01976 & 0.27122 \\
\hline $\begin{array}{c}\text { Root } \\
\text { mean } \\
\text { square }\end{array}$ & 5.43013 & 5.07448 & 5.41239 \\
\hline
\end{tabular}

Table 3. Cokriging(DEM+SAVI), Kriging, IDW Accuracy

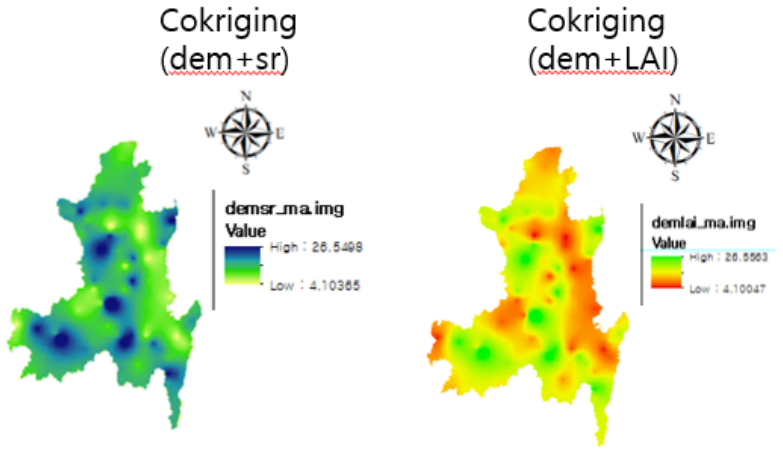

Cokriging

$($ dem $+\mathrm{NDVI})$

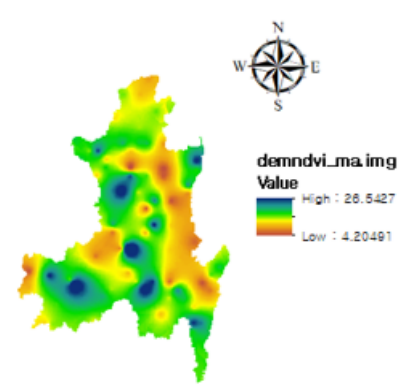

Figure7. Cokriging(DEM+SR), Cokriging(DEM+NDVI), Cokriging(DEM+LAI)

\begin{tabular}{|c|c|c|c|}
\hline & $\begin{array}{l}\text { Cokriging } \\
\text { (DEM+SR) }\end{array}$ & $\begin{array}{l}\text { Cokriging } \\
\text { (DEM+LAI) }\end{array}$ & $\begin{array}{l}\text { Cokriging } \\
\text { (DEM+N } \\
\text { DVI) }\end{array}$ \\
\hline $\begin{array}{c}\text { Mean } \\
\text { error }\end{array}$ & 0.138214 & 0.13608 & 0.1382 \\
\hline $\begin{array}{c}\text { Root } \\
\text { mean } \\
\text { square }\end{array}$ & 5.429842 & 5.43173 & 5.4301 \\
\hline
\end{tabular}

Table 4. Cokriging(DEM+SR), Cokriging(DEM+NDVI), Cokriging(DEM+LAI) Accuracy

Unlike the prediction, the Cokriging interpolated using a secondary variable vegetation index, the result of kriging using only one biodiversity index was better. However, since the correlation between the vegetation index and the biodiversity index is low, it is necessary to research and obtain more data that correlate with the vegetation index and biodiversity index data. Since the number of sample points is relatively small in order to represent and space the whole country, it is necessary to link with other data such as NFI(National Forest Invest) data with a large number of sampling points. Since the size of the survey sample point is smaller than $30 \mathrm{~m}$, which is the resolution of Landsat, Kompsat-2 satellite images with higher resolution and data taken by drone will be studied later.

\section{ACKNOWLEDGEMENTS (OPTIONAL)}

Aknowledgement: This study was carried out with the support of Korea Meteorological Administration as part of Research \& Development Program with a See-At (See+Atmosphere) grant (KMIPA 2015-6140). 


\section{REFERENCES}

Hong, G.d, 1996. Atmospheric correction method of Landsat Tm, Kroean Journal of Remote Sensing, 10(3): 195-172

Hee Moon Yang, Sung Kee Kang, Ji Hong Kim. 2001. Selection of Desirable Species and Estimation of Composition Ratio in a Natural Deciduous Forest. Journal of Korean society of forest science, $100(4), 465-475$

Quan He Chun, Lee Byung Gul, 2009. Analysis of Relationship Between LST and NDVI using Landsat TM Images on the City Areas of Jeju Island. Journal of the Korean Society for Geospatial Information Science 17(4), 2009.12, 39-44

Yoon, Seon Yong, Choi, Hyun, Kim, Gi Hong, 2017. Estimation of Vegetation Cover Fraction Using Landsat 8 OLI imagery and Field Survey Data 25(3), 2017.9, 95-100

Jung Gil Sub, Koo seul, Yoo Hwan Hee, 2011. Temperature Change Analysis for Land Use Zoning Using Landsat Satellite Imagery, Journal of the Korean Society for Geo-spatial Information Science 19(2), 2011.6, 55

Jung-Bin Lee, Seung-Ho Lee, Eun-Sook Kim, 2013. An Analysis of Spectral Pattern of Pine Wilt Disease Using Ground Based Hyperspectral Camera Image, The Korean Society for Geospatial Information Science, 2013.5, 83-86

Hyung-seok Lee, 2010. Comparison and Evaluation of Root Mean Square for Parameter Settings of Spatial Interpolation Method, 2010 13(3). 29 41

Hong-lae Cho, Jong-chul Jeon, 2007. Mapping of Environmental Data Using Spatial Interpolation Methods, 2007.6, 273-279

PARK, Jong-Chul, KIM, Man-Kyu, 2009. A study on the use of a terrain aspect variable in producing the precipitation distribution map applying Cokriging: A case of Jeju Island, Journal of the Korean geomorphological Association. 16(3), 5966

Combining richness and abundance into a single diversity index using matrix analogues of Shannon;s and Simpson;s indices, 2006. Ecography 29: 525-530

Toby N. Carlson, David A. Ripley. 1997. On the relation between NDVI, fractional vegetation cover leaf area index. Remote sensing of environment 62(3) 241-252

Rouse, j. w. Haas, R. H. Schell, J. A. and D. W.Deering., 1974, Monitoring vegetation systems in the great plains with ERTS. Proceedings, 8th international Symposium on Computer Assisted Cartography, Baltimore, MD, pp. 68-77 